\title{
XXIX. Intelligence and miscellaneous articles
}

\section{A. Reirtalf}

To cite this article: A. Reirtalf (1811) XXIX. Intelligence and miscellaneous articles, Philosophical Magazine Series 1, 37:154, 157-158, DOI: 10.1080/14786441108563259

To link to this article: http://dx.doi.org/10.1080/14786441108563259

\section{Published online: 18 May 2009.}

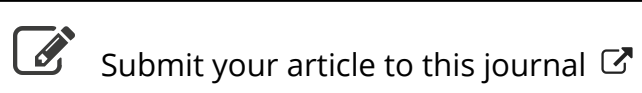

Џll Article views: 2

Q View related articles $\sqsubset$ 
tremity, and have kept the temple confined in a kind of lake until a passage was opened, and restored the ground to its natural dryness? - There are difficulties attending all these explanations, particularly the two last. How could such important changes have taken place after the construction of the temple, and have left no trace in history or in the memory of man? They frequently speak of the eruption in the year 1528, when the hill called Monte-Nuovo was formed, and when the sea invaded a part of the coast; but there is no tradition of successive revolutions. - Near this temple has been discovered a particular variety of marble, of which M. Cubieres has read an analysis to the Institute. It is white, semi-transparent, and receives a fine polish ; it dissolves with difficulty in the nitric acid, and gives sparks with steel; it contains 22 parts in every hundred of magnesia. M. Cubieres has called it the Greck Magnesian Marble, and thinks it the same which the ancients made use of to construct their temples withoul windows, that received light only through the transparent walls.-M. Daubisson has given an account of a mine of lead near Tranowitz in Silesia, containing the ore called galena in a very extensive bed. It is found in rocks composed of shells, which Mr. D. thinks are of recent formation. To know really the age of the calcareous beds in which the lead ore is found, we should determine the species of shells that they contain.

XXIX. Intelligence and Miscellaneous Articles.

To Mr. Tilloch.

Sir, $\mathrm{H}_{\text {aving observed in a late publication of the first }}$ respectability, that the writer of the article on "Freezing Mixtures" regrets that I have not given the specific gravities of the acids used in my experiments; I beg leave to state, for the information of that gentleman, and others whom it may concern, that the specific gravity of the sulphuric acid was 1.848 ; and that of the red fuming nitrous acid 1.510; both of which are thus given in a paper by me in the Philosophical Transactions for 1795 ; and in my Treatise on Artificial Cold, page 76.

I take this opportunity of declaring my intention of presenting, through the medium of the Philosophical Magazine, some observations relating to the practice of Physic and Surgery, collected by me, during a residence of nearly five-and-twenty years in the Radcliffe Infirmary, as apothecary to that institution. 
In the course of the period above mentioned, I had an opportunity of attending to, and watching, nearly all the cases chirurgical as well as medical which occurred, amounting to upwards of nineteen thousand patients; making a journal occasionally, which I have by me, consisting of brief remarks respecting the progress and event of the various diseases which presented, and the effects of the different medicines and applications administered in those diseases.

$I$ have adopted this method of communicating what $I$ may wish to say on this subject, the whole of which will be comprised in a small compass, in consequence of $\mathbf{m y}$ present occupations allowing me scarcely any leisure, even for the purpose of epitomizing the result of my experience.

My chief object therefore will be, to point out, under the form of a compendious classification, the diseases which are curalle, and the most appropriate or efficacious remedies for that purpose; and likewise the means of palliating the effects of such diseases as I consider from experience to be incuralle.

It must be obvious, that out of such a great number of patients, almost every species of disease, as well as a very frequent recurrence of each, must have passed under my notice: hence the discrimination of diseases, and the respective merits of all the medicines and applications then in use, cannot but be extremely familiar to me.

Oxford, Feb. 18, 1.8!1.

I am, sir,

Your obedient servant, RD. WALKER.

P. S.-In the course of my papers, I shall have occasion to mention some small improvements, as I hope, in the practice of surgery, \&c. made by myself.

\section{To Mr. Tilloch.}

Sir,-Mr. Farey's observation on affixing new and separate ideas to established marks or words, is perfectly correct; and had it not been for an error of the printer, he would not have had occasion for the remark; as, by referring to the letter $I$ had the honour of addressing you, it will be seen that the grave accent (') and not the acute accent (') was intended, as the same objection occurred to me at the time. As the form of the character is of no consequence if the idea is approved, the printers can have recourse to any new one which may suit them, only observing not to alter it when once adopted.

I remain with great respect, sir, Your obliged humble servant,

Spitalfields, Feb. 11, 181 l.

A. Reintalfo 